\title{
Rationally blind?
}

\section{Rationality polarizes policy support for color-blindness versus multiculturalism}

\author{
Jonas De keersmaecker ${ }^{1 *}$ orcid: 0000-0002-8062-7422 \\ Katharina Schmid ${ }^{1}$ orcid: 0000-0001-6018-9245
}

Arne Roets ${ }^{2}$ orcid: 0000-0001-5814-1189

Namrata Goyal ${ }^{1}$ orcid: 0000-0001-8466-9841

\begin{abstract}
${ }^{1}$ Universitat Ramon Llull, Esade Business School, Department of People Management and Organisation

Av. Torre Blanca 59, 08172 Sant Cugat - Barcelona, Spain

${ }^{2}$ Ghent University, Department of Developmental, Personality and Social Psychology

H. Dunantlaan 2, 9000 Gent, Belgium
\end{abstract}

The project leading to these results has received funding from "la Caixa" Foundation under the project code LCF/PR/SR19/52540007, Ministerio de Ciencia e Innovación - Agencia Estatal de Investigación (project code: PID2019-111276GB-I00), and from the Secretariat of Universities and Research of the Department of Business and Knowledge of the Generalitat de Catalunya and Ramon Llull University (project code: 2020-URL-Proj-018), all awarded to Katharina Schmid.

*Corresponding author: jonas.dekeersmaecker@esade.edu. Tel: +34 932806162 


\begin{abstract}
Do racial majority members prefer society to be 'color-blind' by rising above racial identities, or 'multicultural' by openly discussing and considering them? We tested an ideology-rationality model to understand support for these diversity perspectives. Results showed that higher levels of conservatism were related to a relative preference for color-blindness over multiculturalism. Crucially, this relationship was qualified by individuals' level of rationality, either operationalized within a dual process theory (Study 1, N=496) or experimentally induced within a tripartite model of cognition (Study 2, $N=497$ ). Specifically, rationality increased ideological alignment; higher levels of rationality guided people high in conservatism towards a stronger preference for color-blindness, but those low in conservatism towards a stronger preference for multiculturalism. These results suggest that rational considerations about racial policies may further divide rather than unify people along ideological lines.
\end{abstract}


Societies are becoming increasingly diverse. How society should approach racial diversity is fiercely debated among politicians, social scientist, and lay people. People hold different opinions on the topic. Why do some people believe that society benefits from ignoring racial characteristics, and who do others believe that society benefits from considering racial characteristics? We propose an ideological-rationality model, holding that among racial majorities, support for color-blind versus multicultural policy is rooted in political ideology and, critically, is bolstered by rationality.

Some believe that society benefits from a color-blindness perspective, referring to the belief that 'race and racial differences should not be taken into account when decisions are made, impressions are formed, and behaviors are enacted' (Apfelbaum et al., 2012, p. 205). Colorblindness entails the view that one should focus on uniform norms for all, and that racial characteristics should be disregarded. Others believe that society would benefit from a multicultural perspective, where racial differences are recognized, appreciated, and openly discussed. Multiculturalism subscribes to the idea that, although no one racial group should be central in society, racial differences do matter, and should be taken into account rather than ignored (Apfelbaum et al., 2012).

At face value, both approaches reflect promising avenues to promoting intergroup harmony (Plaut et al., 2009). If racial differences are acknowledged without judgment - a central corollary of multiculturalism - one will not devaluate those of a different racial background. Likewise, if race is not even considered - a central corollary of color-blindness - one supposedly cannot discriminate on this basis. However, it has been argued that the deemphasizing of group differences within the color-blind view can entail a reinforcement of the current (unequal) social order between racial groups, thereby obviating an equitable society (Forman, 2004). In a color- 
blind society, the majority perspective is dominant, without considering the perspective and cultural background of racial minorities. Color-blindness may thus foster cultural ignorance and risks the denial and perpetuation of racism (Fryberg \& Stephens, 2010). Therefore, rather than promoting equality, some have even argued that color-blindness constitutes a form of racism (Bonilla-Silva, 2003). Although it is important to note that neither perspective is without its limitations (Plaut et al., 2018), empirical research supports the notion that policies and norms representing multiculturalism relative to color-blindness are related to several positive intergroup outcomes (Sasaki \& Vorauer, 2013), such as more positive face-to-face intergroup interactions (Vorauer et al., 2009), less implicit and explicit racial bias (Richeson \& Nussbaum, 2004), less behavioral prejudice (Son Holoien \& Shelton, 2012), a higher probability of detecting racial discrimination (Apfelbaum et al., 2010), and among racial minorities: better academic outcomes (Birnbaum et al., 2020), work engagement (Plaut et al., 2009) and feeling accepted (Meeussen et al. 2014).

A deeper insight of color-blindness and multiculturalism is needed to gain knowledge of intergroup interactions (Rattan \& Ambady, 2013). We propose an ideology-rationality model to advance understanding of racial majorities' support for color-blindness versus multiculturalism. The model holds that 1) people endorse a particular diversity perspective in line with their ideology of conservatism (cf. Kauff et al. 2021; Wolsko et al. 2006), and 2) that higher levels of rationality increase the alignment between one's core ideological beliefs and one's support for the specific diversity perspective.

Two dimensions underlie conservatism (Jost et al., 2003). The first dimension concerns the preference for maintaining the current social order and structure by preservation of tradition. This aspect of conservatism is mainly focusing on social issues, and its authoritarian variant is 
typically captured by Right-Wing Authoritarianism (RWA), characterized by the covariation of conventionalism, authoritarian submission, and authoritarian aggression (Altemeyer, 1981). The second dimension concerns the tolerance and preference for a competitive society with hierarchical and non-egalitarian intergroup relations. This aspect, mainly focusing on economichierarchical issues, is often captured with the concept of Social Dominance Orientation (SDO), referring to one's beliefs about dominance and inequality among social groups (Pratto et al., 1994).

We argue that the core of conservatism aligns more with the color-blindness perspective compared to the multicultural perspective. The fundamental idea of ignoring differences and having uniform norms for all to abide by that is key to the color-blindness perspective, matches well the central tenet of social conservatism and RWA to focus on conventionalism and protecting the existing social order. It also aligns with the competition-inequality core of economic conservatism and SDO; if (historical) group differences are ignored and the same norms, that are set by majority members, apply to everyone, a level playing field for competition is created in which potential preferential outcomes in favor of the dominant majority can be justified as 'fair and unbiased'.

Crucially, we further argue that the relationship between conservatism and a preference for color-blindness over multiculturalism is stronger under higher levels of rationality. Rationality is typically conceptualized within a dual process framework (Stanovich et al., 2016), holding that there are two types of information processing: intuitive thinking (often referred as Type 1) and rational thinking (often referred as Type 2). Intuitive thinking is an automatic process with low involvement of high-level control systems; it is fast and effortless. Rational 
thinking is a fine-grained elaborative process that is computationally expensive - it is slower and more effortful.

How can rationality impact one's endorsement for color-blindness or multiculturalism? People pursue coherent belief systems (Azevedo et al., 2019). Therefore, we propose that people adopt a diversity orientation that maximizes the likelihood of reaching their ideological goals. However, color-blindness and multiculturalism are complex and multilayered ideologies (Mazzocco, 2017). Intuitive thinking might be insufficient to fully capture the true meaning and consequences of both diversity perspectives; it might (erroneously) lead one to conclude that color-blindness and multiculturalism are different means that will result to a similar goal - that of erasing group-based discrimination (Plaut et al., 2009). However, color-blind policies are more likely to retain the (unequal) societal status-quo, while multicultural policies are more likely to generate social change that advances the concerns and status of minority groups. We argue that to fully grasp these different implications underlying the two diversity perspectives, more elaborate reasoning is necessary. Rational decision-making entails making decisions that enable individuals to achieve their personal life goals using the best possible means (Stanovich et al., 2016). Hence, for conservative majority members, whose goal it is to maintain the existing social order, dominance and competition, the 'rational choice' is to prefer color-blindness over multiculturalism. In contrast, for those low in conservatism, whose aim it is to change the existing social order, dominance and competition, the 'rational choice' is to prefer multiculturalism over color-blindness.

We tested our hypothesis in two studies. Specifically, we predicted a positive relationship between conservatism and a relative preference for color-blindness over multiculturalism, which is magnified by individuals' levels of rationality. In both studies, we report all measures, 
manipulations and exclusions. Sample sizes were determined before any data analysis, and data were analyzed after data collection was completed. Data and R-code of the studies are available at https://osf.io/xpytw/?view only=dd4a1855aeaf4aa99b7d42750177d3ed

\section{Study 1}

We tested our ideological-rationality model among US White majority members, examining whether rationality interacted with four measures of conservative ideology to predict preference in color blindness versus multiculturalism.

\section{Method}

Participants. To obtain a power of approximately .90 to detect interaction effects of $\beta=$ .15, we recruited 500 White US citizens on Prolific. Four hundred and ninety-six participants completed the study $\left(M_{\text {age }}=39.87\right.$ years, $S D_{\text {age }}=13.02 ; 296$ identified as male, 188 identified as female, 10 identified as non-binary, and 2 participants preferred not to disclose their gender).

Procedure and materials. First, we asked participants to read two different opinions endorsed ostensibly by different policy makers holding divergent views on minority groups in society. The descriptions represented a color-blindness perspective ('I believe that we should rise above racial, ethnic and cultural differences. I believe that ethnic and racial identities are characteristics that eventually don't matter. Hence, when decisions are made, impressions are formed, and behaviors are enacted, all people should be treated in an identical manner, without regard to race and ethnicity') and a multicultural perspective ('I believe that we should pay attention to racial, ethnic and cultural differences. I believe that, although no group should be central, ethnic and racial identities actually do matter. They should be recognized and openly discussed. Hence, when decisions are made, impressions are formed, and behaviors are enacted, 
we should take into account people's racial and ethnic background'), based on Apfelbaum et al. (2012) and Morris et al. (2015). The labels of color-blindness and multiculturalism were not used in the description. Participants were asked to indicate which policy they preferred on a scale from 1 (strongly prefer policy 1) to 7 (strongly prefer policy 2 ). Responses were recoded such that higher scores indicated a relative preference for color-blindness over multiculturalism.

Next, as indices of ideology, participants completed measures of RWA (11 items; Altemeyer, 1981), SDO (16 items; Pratto et al., 1994), social conservatism (1 item) and economic conservatism (1 item).

Finally, a reworded version of Frederick's (2005), and Toplak et al.'s (2014) cognitive reflection test (CRT) was assessed as an indicator of rationality. This combined scale consists of seven mathematical problems that require only basic mathematical abilities to solve, but that have intuitively compelling incorrect answers. An example item reads, the ages of Lance and John add up 28 in total. Lance is 20 years older than John. How many years old is John? The intuitive response is incorrect, and more cognitive deliberation is needed to come up with the correct response. The test therefore captures individuals' disposition to engage in rational thinking. Descriptive statistics are presented in Table 1. 
Table 1. Descriptive statistics for Study 1 and Study 2.

\begin{tabular}{lcccc}
\hline & Study 1 & & & \\
\hline & Scale range & M & SD & Cronbach $\alpha$ \\
RWA & $1-5$ & 3.10 & 0.83 & .88 \\
SDO & $1-5$ & 1.98 & 0.81 & .94 \\
SOC. CON. & $1-7$ & 3.11 & 1.91 & \\
ECO CON. & $1-7$ & 3.39 & 1.95 & \\
CRT & $0 \%-100 \%$ & 42.08 & 30.17 & .74 \\
Color Bl. vs Multi Cul. & $1-7$ & 4.10 & 2.16 & \\
\hline & Study 2 & & & \\
\hline & Scale range & M & SD & Cronbach $\alpha$ \\
RWA & $1-5$ & 2.82 & 0.78 & .85 \\
SDO & $1-5$ & 1.90 & 0.80 & .94 \\
SOC. CON. & $1-7$ & 3.03 & 1.76 & \\
ECO. CON. & $1-7$ & 3.52 & 1.81 & \\
COGN ABILITY & $0 \%-100 \%$ & 75.22 & 17.24 & .93 \\
Color Bl. vs Multi Cul. & $1-7$ & 4.09 & 2.15 & \\
\hline
\end{tabular}

\section{Results}

To test the predicted ideology-rationality model for the different indicators of ideology, we ran four models in which color-blindness support over multiculturalism was regressed on the centered scores of the respective ideology indicator, the centered scores of the CRT, and their interaction term. Results are presented in Table 2. 
Table 2. Study 1: four models predicting preference for color-blindness relative to multiculturalism as a function of specific ideology, CRT, and their interaction

\begin{tabular}{|c|c|c|c|c|c|c|c|c|}
\hline & \multicolumn{8}{|c|}{ Preference for Color-blindness vs. Multiculturalism } \\
\hline & \multicolumn{2}{|c|}{$\begin{array}{l}\text { Model 1: } \\
\text { IV: RWA }\end{array}$} & \multicolumn{2}{|c|}{$\begin{array}{l}\text { Model 2: } \\
\text { IV: SDO }\end{array}$} & \multicolumn{2}{|c|}{$\begin{array}{c}\text { Model 3: } \\
\text { IV: SOC. CON. }\end{array}$} & \multicolumn{2}{|c|}{$\begin{array}{c}\text { Model 4: } \\
\text { IV: ECO. CON. }\end{array}$} \\
\hline & $\beta$ & $p$ & $\beta$ & $p$ & $\beta$ & $p$ & $\beta$ & $p$ \\
\hline Ideology & $\begin{array}{c}.29 \\
{[.20, .38]}\end{array}$ & $<.001$ & $\begin{array}{c}.11 \\
{[.02, .20]}\end{array}$ & .013 & $\begin{array}{c}.20 \\
{[.11, .29]}\end{array}$ & $<.001$ & $\begin{array}{c}.18 \\
{[.09, .27]}\end{array}$ & $<.001$ \\
\hline CRT & $\begin{array}{c}.10 \\
{[.02, .19]}\end{array}$ & .019 & $\begin{array}{c}.04 \\
{[-.05, .13]}\end{array}$ & .378 & $\begin{array}{c}.07 \\
{[-.02, .16]}\end{array}$ & .105 & $\begin{array}{c}.05 \\
{[-.04, .13]}\end{array}$ & .290 \\
\hline Ideology*CRT & $\begin{array}{c}.08 \\
{[-.00, .16]}\end{array}$ & .057 & $\begin{array}{c}.14 \\
{[.05, .23]}\end{array}$ & .002 & $\begin{array}{c}.19 \\
{[.10, .27]}\end{array}$ & $<.001$ & $\begin{array}{c}.15 \\
{[.07, .23]}\end{array}$ & $<.001$ \\
\hline \multicolumn{9}{|l|}{ Slopes } \\
\hline$-1 \mathrm{SD}$ CRT & $\begin{array}{c}.21 \\
{[.08, .34]}\end{array}$ & .001 & $\begin{array}{c}-.03 \\
{[-.15, .09]}\end{array}$ & .621 & $\begin{array}{c}.01 \\
{[-.10, .12]}\end{array}$ & .854 & $\begin{array}{c}.03 \\
{[-.09, .14]}\end{array}$ & .653 \\
\hline$+1 \mathrm{SD}$ CRT & $\begin{array}{c}.37 \\
{[.26, .48]}\end{array}$ & $<.001$ & $\begin{array}{c}.25 \\
{[.12, .38]}\end{array}$ & $<.001$ & $\begin{array}{c}.38 \\
{[.24, .52]}\end{array}$ & $<.001$ & $\begin{array}{c}.33 \\
{[.20, .46]}\end{array}$ & $<.001$ \\
\hline
\end{tabular}

Note. Coefficients are standardized. Values between brackets represent $95 \%$ confidence intervals. 'Ideology' refers to the specific ideology considered as independent variable (IV) in each model (Model 1: RWA, Model 2: SDO, Model 3: Social conservatism, Model 4: Economic conservatism).

As expected, higher scores on all four indicators of conservatism (RWA, SDO, social conservatism, economic conservatism) were related to a relative preference for color-blindness over multiculturalism. Importantly, these relationships were moderated by CRT-scores. The interaction pattern was consistent across the four indicators of ideology (see Figure 1); the relationship between conservative ideology and a preference for color-blindness over multiculturalism was driven in particular by participants showing higher reflective thinking on the CRT. The interaction was marginally significant for RWA, and statistically significant for the other indicators of conservatism. Thus, individuals were particularly likely to endorse colorblindness over multiculturalism if they were higher in ideological conservatism and rational thinking. 
Figure 1. The relationship between ideology and attitudes towards color-blindness relative to multiculturalism, depending on CRT scores

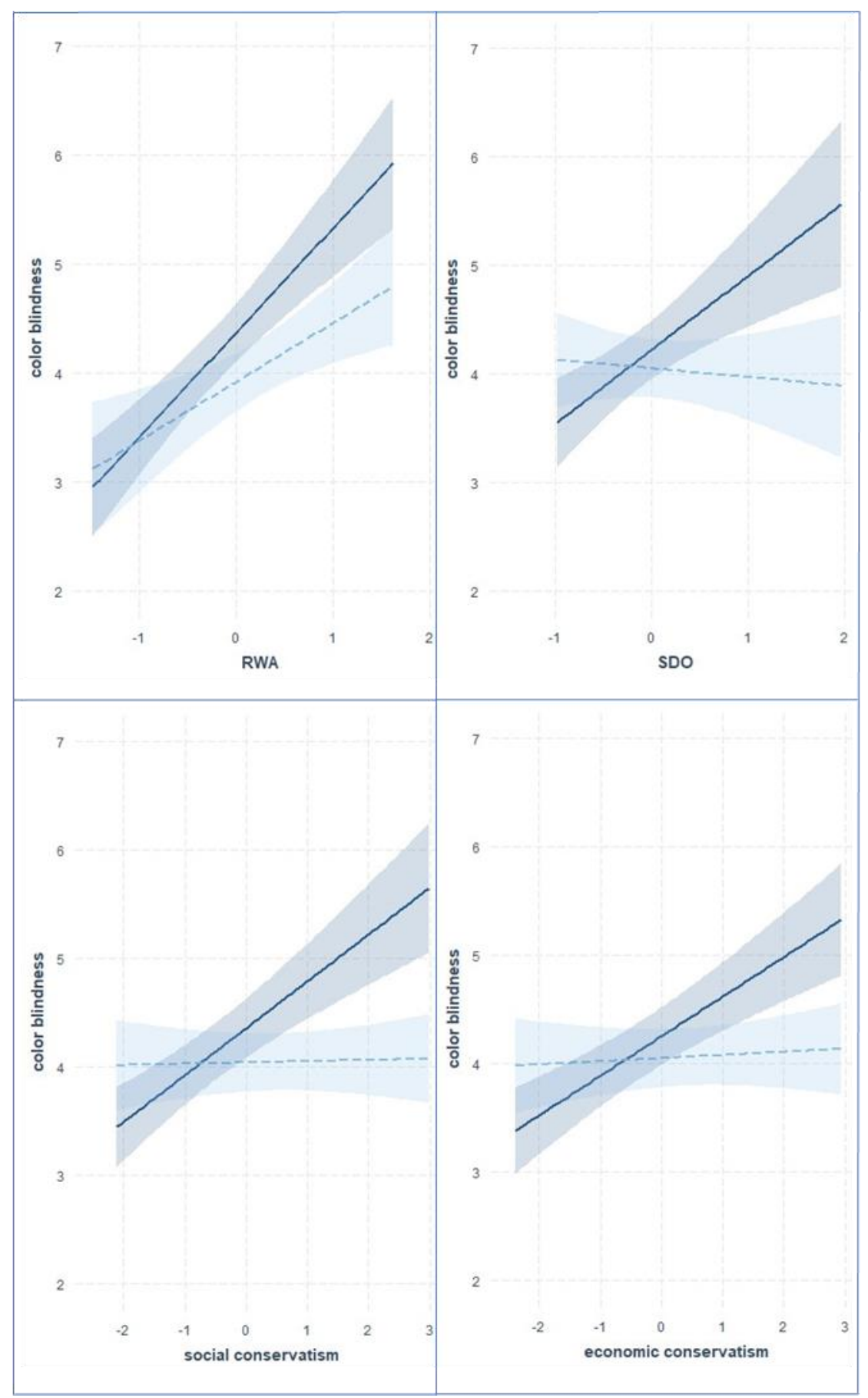

Note. The full line represents mean + 1SD on the CRT and its 95\% confidence interval, the dotted line represents mean - 1SD on the CRT and its 95\% confidence interval. 


\section{Study 2}

In Study 1, we operationalized rationality within a dual-process theory. We used the CRT; capturing the thinking style to override intuitively appealing responses in favor of more

elaborated ones (Frederick 2005). However, although the CRT assesses 'thinking style', some have argued that performance on the test is aided to a certain degree by 'thinking ability' (see e.g. Sobkow et al. 2020).

More recently, Stanovich et al. (2016) incorporated the dual-process theory of rationality into a tripartite model of cognition. This conceptual model explicitly differentiates between 'thinking style' and 'thinking ability', and rationality results from an interplay between both cognitive systems. Thinking style refers to whether someone relies on automatic cognitive processing (i.e., intuitive thinking), or engages in elaborative and higher order cognitive processing (i.e., rational thinking). Thinking ability refers to cognitive ability or 'intelligence', one's maximal ability to conduct higher cognitive processes of reasoning. This tripartite model thus holds that rationality is the result of both: 1) allocating sufficient cognitive resources to the problem (i.e., engaging in rational rather intuitive thinking) and 2) having sufficient cognitive capabilities to process the information and solve the problem (i.e., cognitive ability).

In Study 2, we aimed to replicate the ideology-rationality model, building on this more recent account of rationality. Specifically, we differentiated more clearly between thinking ability and thinking style, by measuring ability and experimentally manipulating style. Hence, we tested a more fine-grained prediction in Study 2, that when it comes to supporting particular diversity orientations, 1) individuals endorse a perspective that is in line with their core ideological attitudes, and 2) they do so especially when they engage in elaborative reasoning on 
the diversity perspective and have more cognitive capabilities to process relevant information adequately.

\section{Method}

Participants. Precision simulations of our hypothesized model indicated that $N=500$ would result in an average deviation of the sample from the true parameter of the three-way interaction of .08 , resulting to a precision within \pm .16 with $95 \%$ confidence. Five hundred White US citizens were recruited on Prolific. Three participants were omitted from the sample because they did not follow the instructions, leading to a final sample size of 497 ( $M_{\text {age }}=38.71$ years, $S D_{\text {age }}=12.80,245$ identified as male, 245 identified as female, 6 identified as non-binary, and 1 participant preferred not to disclose their gender).

Procedure and materials. First, participants completed the same measures of RWA, SDO, social conservatism, and economic conservatism as in Study 1.

Next, participants were presented with the same description of color-blindness and multiculturalism as in Study 1. We experimentally induced thinking style by assigning participants randomly to a no reflection or a reflection condition. In the no reflection condition, identical to Study 1, participants were merely asked to indicate which policy they preferred. In the reflection condition, participants were presented with a textbox, and instructed as follows: 'Please reflect on both policies. What do you think about these policies? Write down your thoughts' (for a similar procedure of inducing reflective thinking in the context of mathematical problems, see Isler et al., 2020). Subsequently they were asked to indicate their preference for color-blindness relative to multiculturalism ${ }^{1}$.

\footnotetext{
${ }^{1}$ As a proxy to gauge the extent of participants' elaboration; participants in the no reflection condition spent on average 49 seconds between the start of the presentation of the policies and
} 
Finally, participants completed the Ammons Quick Test (Ammons \& Ammons, 1962). In this cognitive ability test, participants are presented with four pictures and a list of 50 words, and are asked to assign each word to the picture that is the best match. Descriptive statistics are presented in Table 1.

\section{Results}

We tested the ideology-rational model for the different indicators of conservative ideology. Since rationality was conceptualized as the interplay between thinking style and thinking ability, we ran four models in which support for color-blindness over multiculturalism was regressed on the centered scores of the ideology indicator, condition $(-1=$ no reflection; $1=$ reflection), centered scores of cognitive ability, as well as their two-way interactions, and the three-way interactions, respectively.

indicating their preference, whereas participants in the reflection condition spent on average 198 seconds to decide which policy they preferred, $F(1,495)=255.55, p<.001$, partial eta squared $=$ .34 . 
Table 3. Study 2: four models predicting preference for color-blindness relative to multiculturalism as a function of specific ideology, cognitive ability, condition, its two-way interactions, and its three-way interaction.

\begin{tabular}{|c|c|c|c|c|c|c|c|c|}
\hline & \multicolumn{8}{|c|}{ Preference for Color-blindness vs. Multiculturalism } \\
\hline & \multicolumn{2}{|c|}{$\begin{array}{l}\text { Model 1: } \\
\text { IV: RWA }\end{array}$} & \multicolumn{2}{|c|}{$\begin{array}{l}\text { Model 2: } \\
\text { IV: SDO }\end{array}$} & \multicolumn{2}{|c|}{$\begin{array}{c}\text { Model 3: } \\
\text { IV: SOC. CON. }\end{array}$} & \multicolumn{2}{|c|}{$\begin{array}{c}\text { Model4: } \\
\text { IV: ECO. CON. }\end{array}$} \\
\hline & $\beta$ & $p$ & $\beta$ & $p$ & $B$ & $p$ & $\beta$ & $p$ \\
\hline Ideology & $\begin{array}{c}.36 \\
{[.27, .45]}\end{array}$ & $<.001$ & $\begin{array}{c}.22 \\
{[.12, .31]}\end{array}$ & $<.001$ & $\begin{array}{c}.31 \\
{[.23, .40]}\end{array}$ & $<.001$ & $\begin{array}{c}.30 \\
{[.22, .39]}\end{array}$ & $<.001$ \\
\hline Cogn. Ab. & $\begin{array}{c}.00 \\
{[-.10, .10]}\end{array}$ & .985 & $\begin{array}{c}-.11 \\
{[-.21,-.00]}\end{array}$ & .048 & $\begin{array}{c}-.07 \\
{[-.16, .02]}\end{array}$ & .118 & $\begin{array}{c}-.06 \\
{[-.15, .02]}\end{array}$ & .152 \\
\hline Condition & $\begin{array}{c}-.00 \\
{[-.09, .09]}\end{array}$ & .984 & $\begin{array}{c}-.02 \\
{[-.11, .07]}\end{array}$ & .648 & $\begin{array}{c}-.02 \\
{[-.10, .07]}\end{array}$ & .657 & $\begin{array}{c}-.04 \\
{[-.12, .04]}\end{array}$ & .339 \\
\hline Ideology*Cogn. Ab. & $\begin{array}{c}.14 \\
{[.05, .23]}\end{array}$ & .002 & $\begin{array}{c}.16 \\
{[.07, .24]}\end{array}$ & $<.001$ & $\begin{array}{c}.14 \\
{[.05, .22]}\end{array}$ & .001 & $\begin{array}{c}.08 \\
{[-.01, .16]}\end{array}$ & .082 \\
\hline Ideology*Condition & $\begin{array}{c}.08 \\
{[-.01, .17]}\end{array}$ & .081 & $\begin{array}{c}-.01 \\
{[-.11, .08]}\end{array}$ & .772 & $\begin{array}{c}.02 \\
{[-.07, .10]}\end{array}$ & .685 & $\begin{array}{c}.06 \\
{[-.03, .14]}\end{array}$ & .178 \\
\hline Cogn. Ab. *Condition & $\begin{array}{c}-.05 \\
{[-.15, .05]}\end{array}$ & .301 & $\begin{array}{c}-.13 \\
{[-.23,-.02]}\end{array}$ & .018 & $\begin{array}{c}-.09 \\
{[-.18,-.00]}\end{array}$ & .045 & $\begin{array}{c}-.05 \\
{[-.14, .03]}\end{array}$ & .217 \\
\hline Ideology*Cogn. Ab. ${ }^{*}$ Condition & $\begin{array}{c}.09 \\
{[.01, .18]}\end{array}$ & .038 & $\begin{array}{c}.11 \\
{[.02, .19]}\end{array}$ & .015 & $\begin{array}{c}.12 \\
{[.03, .20]}\end{array}$ & .005 & $\begin{array}{c}.07 \\
{[-.01, .16]}\end{array}$ & .099 \\
\hline \multicolumn{9}{|l|}{ Slopes: No Reflection } \\
\hline-1 SD Cogn. Ab. & $\begin{array}{c}.24 \\
{[.06, .42]}\end{array}$ & .010 & $\begin{array}{c}.18 \\
{[.01, .35]}\end{array}$ & .041 & $\begin{array}{c}.28 \\
{[.12, .43]}\end{array}$ & .001 & $\begin{array}{c}.24 \\
{[.07, .41]}\end{array}$ & .005 \\
\hline +1 SD Cogn. Ab. & $\begin{array}{c}.33 \\
{[.16, .49]}\end{array}$ & $<.001$ & $\begin{array}{c}.28 \\
{[.10, .46]}\end{array}$ & .003 & $\begin{array}{c}.31 \\
{[.15, .48]}\end{array}$ & $<.001$ & $\begin{array}{c}.25 \\
{[.09, .41]}\end{array}$ & .002 \\
\hline \multicolumn{9}{|l|}{ Slopes: Reflection } \\
\hline -1 SD Cogn. Ab. & $\begin{array}{c}.21 \\
{[.03, .39]}\end{array}$ & .023 & $\begin{array}{c}-.06 \\
{[-.23, .11]}\end{array}$ & .492 & $\begin{array}{c}.07 \\
{[-.11, .26]}\end{array}$ & .432 & $\begin{array}{c}.21 \\
{[.03, .39]}\end{array}$ & .021 \\
\hline +1 SD Cogn. Ab. & $\begin{array}{c}.68 \\
{[.49, .86]}\end{array}$ & $<.001$ & $\begin{array}{c}.47 \\
{[.29, .64]}\end{array}$ & $<.001$ & $\begin{array}{c}.59 \\
{[.42, .76]}\end{array}$ & $<.001$ & $\begin{array}{c}.51 \\
{[.34, .68]}\end{array}$ & $<.001$ \\
\hline
\end{tabular}

Note. Coefficients are standardized. Values between brackets represent $95 \%$ confidence intervals. 'Ideology' refers to the specific ideology considered as independent variable (IV) in each model (Model 1: RWA, Model 2: SDO, Model 3: Social conservatism, Model 4: Economic conservatism)

Results are presented in Table 3. Higher levels on the four measures of conservatism (RWA, SDO, social conservatism, economic conservatism) were associated with a preference for color-blindness over multiculturalism. Critically, these relationships were moderated by rationality. The interaction pattern was consistent among the four ideological measures (see 
Figure 2). The relationship between ideology and a preference for color-blindness over multiculturalism was most pronounced under high levels of rationality, i.e., for individuals who had higher cognitive abilities and engaged in reflective thinking. More specifically, the relationship between conservatism and a relative preference for color-blindness (main effect of ideology) was more pronounced among individuals with relatively higher levels of cognitive ability (two-way interaction between ideology and cognitive ability), and this pattern was strengthened when individuals were prompted to engage in reflective thinking (three-way interaction between ideology, cognitive ability, and reflective thinking). This pattern was consistent and statistically significant for all indicators of ideology, except for economic conservatism where the interaction was only marginally significant. Hence, using an experimental approach, Study 2 replicates Study 1 showing that the relationship between conservatism and a preference for color-blindness versus multiculturalism is especially pronounced among rational individuals. 
Figure 2. The relationship between ideology and attitudes towards color-blindness relative multiculturalism, depending on the interplay of reflective thinking and cognitive ability

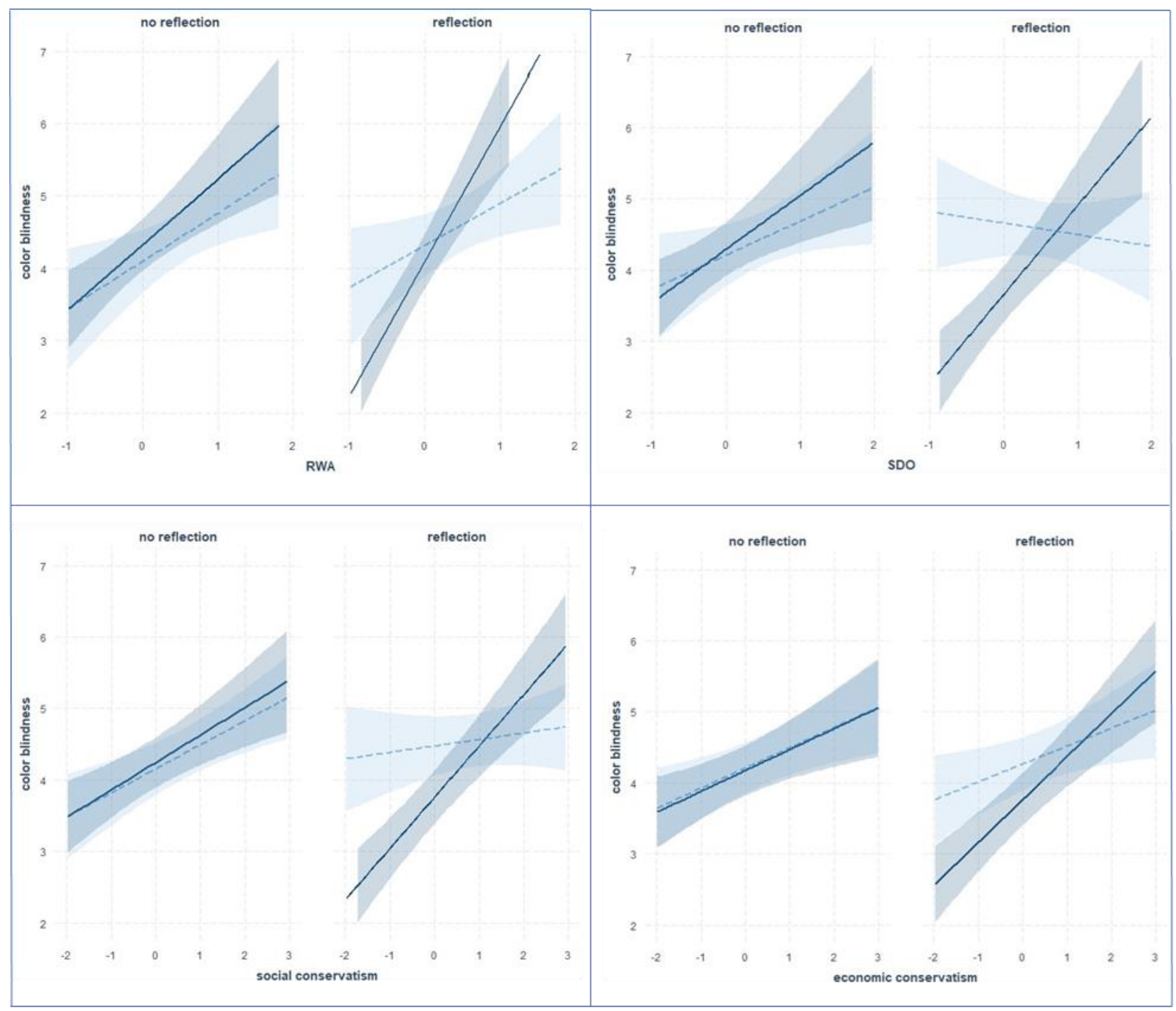

Note. The full line represents mean $+1 \mathrm{SD}$ on the cognitive ability measure and its $95 \%$ confidence interval, the dotted line represents mean - 1SD on the cognitive ability measure and its 95\% confidence interval. For each ideological measure, the left panel represents scores in the no reflection condition, the right panel represent scores in the reflection condition. 


\section{Discussion}

We found that racial majorities' support for color-blindness versus multiculturalism is a result of the interplay between their conservative ideological orientations and levels of rationality. Higher levels of conservatism were related to a relative preference for colorblindness, whereas lower levels of conservatism were related to a relative preference for multiculturalism. Critically, this pattern manifested mainly among relatively more rational individuals. This indicates that people support diversity positions and policies that align with their core ideological values, and that rationality increases the coherence of one's belief system.

Results showed that participants who were most likely to be able to rationally analyze and understand the policies displayed attitudes that aligned more strongly with their core ideological beliefs. Among similar lines, Kahan et al. (2012) found a polarizing role of science literacy on the relationship between cultural world views and perceptions of climate change risk. These results indicate that polarized attitudes about policies in the left-wing or right-wing direction should not be perceived as irrational, inconsiderate opinions, or stemming from lazy cognition. Given one's ideological core values, the endorsement of relatively more outspoken or 'extreme' attitudes about certain policies can originate from rational means to attain one's ideological goals. Consequently, appeals to encourage elaboration in order to change minds and thereby garner support for a particular opposing policy may be ineffective. Instead, they may even further entrench people in their ideology-congruent convictions about which policy is preferable.

In Study 2, we adopted a novel perspective and methodological approach on cognition by operationalizing rationality as the interplay between thinking ability and thinking style (based on Stanovich et al., 2016), and experimentally manipulating thinking style (based on Isler et al., 2020). The observation that asking people to actively reflect on policies causes a stronger 
alignment between one's ideology and policy preferences, but only among those with relatively more cognitive abilities, signifies the theoretical and methodological importance to distinguish between cognitive styles and cognitive abilities, and consider their potential interplay. This interplay between thinking ability and thinking style has the potential to advance understanding of judgment and decision making across many domains, but is largely neglected in the empirical literature.

Our results also highlight the importance of situational and contextual factors in politics. There are times in which people engage in or are prompted to engage in more elaborative reasoning about diversity policies, for example in the run-up to elections or when incidents take place that get a lot of (social) media attention. In situations such as these, the opinions of individuals with left versus right leaning political orientations might diverge as a consequence of elaboration. Moreover, this process is likely to be further reinforced since people often discuss political issues in echo chambers (Cinelli et al., 2021), and the discussion of thoughts and opinions among like-minded people leads to more extreme opinions (Schkade et al., 2010).

Importantly, Knowles et al. (2009) showed that the term 'color-blindness' might mean something different depending on one's political ideology and perceptions of intergroup threat. Specifically, high levels of threat prompt racial majorities high in SDO to define the concept of color-blindness relatively more in terms of a procedural justice than a distributive justice principle. For this reason, we avoided the ideology-loaded terms of color-blindness and multiculturalism in our experiments. Since no single standard measurement method exists to assess attitudes towards color-blindness and multiculturalism (Mazzocco, 2017), and different investigations use slightly different conceptualizations of color-blindness and multiculturalism (Plaut et al., 2018), we operationalized color-blindness and multiculturalism based on their most 
central defining characteristic, i.e. beliefs about whether racial characteristics matter, and should be considered or not (see e.g. Apfelbaum et al. 2012). However, we wish to point out that other scholars have developed multi-faceted theoretical models of color-blindness. For example, Mazzocco (2017) identified different variations of color-blindness, based upon people's degree of egalitarianism and awareness of racial inequality. Future research with a more direct focus on color-blindness might examine differences in the endorsement of these subtypes of colorblindness.

We focused on the US in the present investigation, a most relevant context given its racial disparities and growing diversity. The results were robust, with comparable effects across two different studies, four different operationalizations of conservative ideology, and two different operationalizations of rationality. Nevertheless, we caution against generalizing the results across contexts and time. Relationships between ideological orientations and intergroup attitudes are context dependent (Roets et al., 2015), and changes in societal awareness about color-blindness and multiculturalism might impact the outcomes.

To conclude, rationality polarizes diversity attitudes along ideological lines among White Americans. That is, rationality guides conservative racial majorities towards a preference for color-blindness, and liberal racial majorities towards a preference for multiculturalism, as either policy presents a rational means to achieve their differently valued ideals. Therefore, ironically, rational appeals may thus further divide rather than unify public opinion on key social issues. 


\section{References}

Altemeyer, B. (1981). Right-Wing Authoritarianism. Winnipeg: University of Manitoba Press.

Ammons, R.B., \& Ammons, C.H. (1962). Quick Test. Oxford, England: Psychological Test Specialists.

Apfelbaum, E.P., Norton, M.I., \& Sommers, S.R. (2012). Racial color blindness: Emergence, practice, and implications. Current directions in psychological science, 21, 205-209.

Apfelbaum, E.P., Pauker, K., Sommers, S.R., \& Ambady, N. (2010). In blind pursuit of racial equality?. Psychological Science, 21, 1587-1592.

Azevedo, F., Jost, J. T., Rothmund, T., \& Sterling, J. (2019). Neoliberal ideology and the justification of inequality in capitalist societies: Why social and economic dimensions of ideology are intertwined. Journal of Social Issues, 75, 49-88.

Birnbaum, H.J., Stephens, N.M., Townsend, S. S., \& Hamedani, M.G. (2020). A diversity ideology intervention: Multiculturalism reduces the racial achievement gap. Social Psychological and Personality Science, 1948550620938227.

Bonilla-Silva, E. (2003). Racism without racists: Color-blind racism and the persistence of racial inequality in the United States. Lanham, MD: Rowman \& Littlefield.

Cinelli, M., Morales, G.D.F., Galeazzi, A., Quattrociocchi, W., \& Starnini, M. (2021). The echo chamber effect on social media. Proceedings of the National Academy of Sciences, 118, e2023301118. 
Forman, T.A. (2004). Color-blind racism and racial indifference: The role of racial apathy in facilitating enduring inequalitites. In M. Krysan \& A. Lewis (Eds.), The changing terrain of race and ethnicity (pp. 43-66). New York: Russell Sage Foundation.

Frederick, S. (2005). Cognitive reflection and decision making. Journal of Economic perspectives, 19, 25-42.

Fryberg, S.A., \& Stephens, N.M. (2010). When the world is colorblind, American Indians are invisible: A diversity science approach. Psychological Inquiry, 21, 115-119.

Holoien, D.S., \& Shelton, J.N. (2012). You deplete me: The cognitive costs of colorblindness on ethnic minorities. Journal of Experimental Social Psychology, 48, 562-565.

Isler, O., Y1lmaz, O., \& Doğruyol, B. (2020). Activating reflective thinking with decision justification and debiasing training. Judgment and Decision Making, 15, 962-938.

Jost, J.T., Glaser, J., Kruglanski, A.W., \& Sulloway, F.J. (2003). Political conservatism as motivated social cognition. Psychological Bulletin, 129, 339-375.

Kahan, D.M., Peters, E., Wittlin, M., Slovic, P., Ouellette, L.L., Braman, D., \& Mandel, G. (2012). The polarizing impact of science literacy and numeracy on perceived climate change risks. Nature Climate Change, 2, 732-735.

Kauff, M., Asbrock, F., \& Schmid, K. (2021). Pro-diversity beliefs and intergroup relations. European Review of Social Psychology, 32, 269-304. 
Knowles, E. D., Lowery, B. S., Hogan, C. M., \& Chow, R. M. (2009). On the malleability of ideology: Motivated construals of color blindness. Journal of Personality and Social Psychology, 96, 857-869.

Mazzocco, P. J. (2017). The psychology of racial colorblindness: A critical review. New York, NY: Palgrave Macmillan.

Meeussen, L., Otten, S., \& Phalet, K. (2014). Managing diversity: How leaders’ multiculturalism and colorblindness affect work group functioning. Group Processes \& Intergroup Relations, 17, 629-644.

Morris, M.W., Chiu, C-y., \& Liu, Z. (2015). Polycultural psychology. Annual Review of Psychology, 66, 631-659.

Plaut, V.C., Thomas, K.M., \& Goren, M.J. (2009). Is multiculturalism or color blindness better for minorities?. Psychological Science, 20, 444-446.

Plaut, V. C., Thomas, K. M., Hurd, K., \& Romano, C. A. (2018). Do color blindness and multiculturalism remedy or foster discrimination and racism?. Current Directions in Psychological Science, 27, 200-206.

Pratto, F., Sidanius, J., Stallworth, L.M., \& Malle, B.F. (1994). Social dominance orientation: A personality variable predicting social and political attitudes. Journal of Personality and Social Psychology, 67, 741-763.

Rattan, A., \& Ambady, N. (2013). Diversity ideologies and intergroup relations: An examination of colorblindness and multiculturalism. European Journal of Social Psychology, 43, 12-21. 
Richeson, J.A., \& Nussbaum, R.J. (2004). The impact of multiculturalism versus colorblindness on racial bias. Journal of Experimental Social Psychology, 40, 417-423.

Roets, A., Au, E. W., \& Van Hiel, A. (2015). Can authoritarianism lead to greater liking of out-groups? The intriguing case of Singapore. Psychological Science, 26, 19721974.

Sasaki, S. J., \& Vorauer, J. D. (2013). Ignoring versus exploring differences between groups: Effects of salient color-blindness and multiculturalism on intergroup attitudes and behavior. Social and Personality Psychology Compass, 7, 246-259.

Schkade, D., Sunstein, C. R., \& Hastie, R. (2010). When deliberation produces extremism. Critical Review, 22, 227-252.

Sobkow, A., Olszewska, A., \& Traczyk, J. (2020). Multiple numeric competencies predict decision outcomes beyond fluid intelligence and cognitive reflection. Intelligence, 80, 101452.

Stanovich, K.E., West, R.F., \& Toplak, M.E. (2016). The rationality quotient: Toward a test of rational thinking. Cambridge: MIT press.

Toplak, M.E., West, R.F., \& Stanovich, K.E. (2014). Assessing miserly information processing: An expansion of the cognitive reflection test. Thinking \& Reasoning, 20, 147-168.

Vorauer, J.D., Gagnon, A., \& Sasaki, S.J. (2009). Salient intergroup ideology and intergroup interaction. Psychological Science, 20, 838-845. 
Wolsko, C., Park, B., \& Judd, C. M. (2006). Considering the tower of Babel: Correlates of assimilation and multiculturalism among ethnic minority and majority groups in the United States. Social Justice Research, 19, 277-306. 